\title{
A obra aberta de Qorpo-Santo
}

\section{Thiago de Freitas}

\begin{abstract}
Resumo: Em 1877 o gaúcho José Joaquim de Campos Leão Qorpo-Santo imprimiu por conta própria, com a exceção de um dos nove volumes, sua obra completa, a Ensiqlopédia ou Seis mezes de huma enfermidade. A construção do projeto enciclopédico revela em alguns momentos um processo de criação conturbado, como se o autor tivesse correndo contra o tempo, sem possibilidades de correções, às vezes em um fluxo ininterrupto. $\mathrm{O}$ teatro, por exemplo, todo ele datado, teria sido escrito em apenas seis meses, de janeiro a junho de 1866. O presente trabalho gira em torno de uma poética da obra aberta que Qorpo-Santo concede ao leitor. Uma liberdade de intervenção que parte de uma consciência própria de que sua obra é incompleta, talvez até mesmo imperfeita. Ironicamente, o dramaturgo gaúcho intitulou sua obra completa de Ensiqlopédia, o que sugere uma pretensão de universalidade, de completude. No entanto, o que se realiza é um teatro repleto de imperfeições, não estéticas, mas reflexo da condição humana, de um mundo caótico e fragmentado.
\end{abstract}

Palavras-chave: Qorpo-Santo; Criação literária; Obra aberta; Teatro brasileiro.

\begin{abstract}
In 1877 José Joaquim de Campos Leão Qorpo-Santo privately printed, with the exception of one of the nine volumes, his complete work, Ensiqlopédia ou Seis mezes de huma enfermidade. The construction of the encyclopedia project reveals at times a troubled process of creation, as if the author had a race against time, with no possible corrections, sometimes in an uninterrupted flow. The theater, for example, all of it dated, was written in only six months, from January to June 1866. This work revolves around a poetic of an openwork that QorpoSanto gives to the reader. A freedom of speech that comes from a self-consciousness that his work is incomplete, perhaps even imperfect. Ironically, the playwright titled his work Ensiqlopédia (encyclopedia), suggesting universality. However, what takes place is a theater full of imperfections, not aesthetic, but a reflection of the human condition, of a chaotic and fragmented world.
\end{abstract}

Keywords: Qorpo-Santo; Literary creation; Open work; Brazilian theater.

\section{Enquanto imprimia ${ }^{1}$ em 1877 a Enciqlopédia ou Seis mezes de huma enfermidade, sua} obra completa, José Joaquim de Qampos Leão Qorpo-Santo fez uma importante observação quanto à condição de seu teatro, divido por ele mesmo em romances e comédias:

\footnotetext{
Julgamos, quando começamos a imprimir este livro, que não bastariam as comédias para preenchê-lo; e por isso escrevemos em seu princípio:

As pessoas que comprarem e quiserem levar à cena qualquer das minhas comédias podem bem como fazer quaisquer ligeiras alterações, corrigir alguns erros e algumas faltas, quer de composição, quer de impressão, que a mim por numerosos estorvos foi impossível.

Porto Alegre, terça-feira, 17 de julho de 1877.

$\mathrm{O}$ autor

José Joaquim de Qampos Leão Qorpo-Santo

(QORPO-SANTO, 2001, p. 125-126)
}

\footnotetext{
" Mestrando em Literatura e Diversidade Cultural pela UEFS.

$1 \mathrm{O}$ autor gaúcho editou e imprimiu por conta própria, em sua Tipografia-Qorpo-Santo, quase todos os livros que integram sua Enciqlopédia, com a exceção de um.
} 
Sua noção de obra aberta expressa no convite chama a atenção para que outros autores, no sentido amplo da palavra, participem do texto, ora a acrescentar valores estéticos, corrigir possíveis erros de composição ou de impressão, ora a modificá-lo para adaptações cênicas. Com tal proposta, o autor, ao se comunicar com o leitor, abre uma gama de possibilidades para que seja possível encenar suas peças da melhor maneira, realizando um teatro participativo impensável à época, o final do século XIX.

É verdade, no entanto, que já Miguel de Cervantes no clássico prólogo do Dom Quixote de la Mancha, um tanto ironicamente, alfinetando os livros de cavalaria, alerta o leitor para os supostos problemas que poderão ser encontrados ao longo do livro. Apesar de dialogar com o receptor, a obra já está escrita; apesar de aberta, ela é restrita. Resta então ao leitor com a obra em mãos, diante do prólogo, duas opções: submeter-se às condições do autor ou demitir-se. ${ }^{2}$

Quebrando este paradigma, Pierre Menard, personagem de Jorge Luis Borges no conto "Pierre Menard, autor do Quixote", tentou "reescrever" a obra à sua maneira. Alegoricamente, Menard, apesar de não pretender fazer um novo Quixote mas reproduzir fielmente o livro, se apresenta como uma interpretação, entre tantas outras, do romance de Cervantes. Esta relação nos parece análoga ao ato complementar e participativo do intérprete, uma espécie de transferência de foco: do produtor da obra para seu receptor, que dialoga com ela. Nas palavras do teórico francês Antoine Compagnon "o autor cede, pois, o lugar principal à escritura, ao texto, ou ainda, ao 'escriptor'. [...] O sujeito da enunciação [...] não preexiste à sua enunciação mas se produz com ela, aqui e agora." (COMPAGNON, 2001, p. 50-51)

Diferente do texto narrativo, à dramaturgia, para existir em sua completude, é necessária a encenação, a participação no palco de atores e diretores. Evidente que o drama preexiste aos palcos, mas sua totalidade depende em parte desta condição. Aliado a esta ideia, ao leitor das peças de Qorpo-Santo ainda cabe a reescritura propriamente dita, pelo menos quando se trata de convertê-las aos palcos, como evidencia o autor em sua observação de 1877. Neste ponto, a abertura concedida pelo escritor gaúcho é diferente, por exemplo, do Dom Quixote, livro por vezes indiretamente referenciado em suas peças e talvez de grande importância em sua vida literária. Em pleno auge do prestígio do homem como indivíduo, Qorpo-Santo, conscientemente ou não, soube relativizar sua condição de autor como único

2 Aqui levamos em consideração, sem levantar juízo de valor, os conceitos de Roland Barthes e Michel Foucault em relação à morte do autor. 
princípio explicador da obra de arte. Os artistas de seu século, por outro lado, estavam bem distantes de serem criticamente conscientes dessa realidade.

Umberto Eco, em Obra aberta, observa muito bem essa condição da literatura contemporânea quando afirma que

\begin{abstract}
A poética da obra "aberta" tende, como diz Pousseur, a promover no intérprete "atos de liberdade consciente", pô-lo como centro ativo de uma rêde de relações inesgotáveis, entre as quais ele instaura sua própria forma, sem ser determinado por uma necessidade que the prescreva os modos definitivos de organização da obra fruída; mas [...] poder-se-ia objetar que qualquer obra de arte, embora não se entregue materialmente inacabada, exige uma resposta livre e inventiva, mesmo porque não poderá ser realmente compreendida se o intérprete não a reinventar num ato de congenialidade com o autor. (ECO, 1976, p. 41-42)
\end{abstract}

Ainda sob esta perspectiva, na página final de um dos livros que integra a Ensiqlopédia, o livro número 1, Poezia e Proza, encontramos o poema Hum Adeus, que visualmente, junto a outros três (Censura, Fé e Gratidão), encerram a obra dispostos em forma de crucifixo, formando um poema visual de intensa significação estética.

\footnotetext{
Hum Adeus

Cesso a vida de - qompòr

Cesso a vida d'esqritòr;

Passo a rever minhas obras;

Passo a cortar-lhe as sobras.

Passo a ezaminar-lh'os érros, A decepal'os passo à ferros.

(QORPO-SANTO, 1877, p. 33)
}

Qorpo-Santo, ao fechar seu livro de poesia incluindo, entre outros, o poema acima, deixa claro que sua obra está em aberto, inclusive para ele mesmo. Essa liberdade de intervenção parte de uma consciência própria de que sua obra é incompleta, talvez até mesmo imperfeita. Ironicamente, o dramaturgo gaúcho intitulou sua obra completa de Ensiqlopédia, o que sugere uma pretensão de universalidade, de completude. No entanto, o que se realiza é um teatro repleto de imperfeições, não estéticas, mas reflexo da condição humana, de um mundo caótico e fragmentado.

A imperfeição referida, além de expor a desarmonia e as incoerências da sociedade, está intimamente relacionada ao que consideramos um conturbado processo de criação. Os textos de sua Ensiqlopédia teriam sido compostos entre 1852 e 1877. Apesar destes 25 anos, o autor passou alguns deles lutando juridicamente e interdito, acusado injustamente de não poder gerir seus bens nem a si próprio, por causa de uma suposta doença mental. $\mathrm{O}$ teatro, por exemplo, todo ele datado, foi escrito em apenas seis meses (entre janeiro e julho de 1866) e, como indica em algumas peças o próprio autor, de uma só sentada, como se estivesse 
correndo contra o tempo, sem correções posteriores, às vezes num fluxo ininterrupto de criação.

Alguns exemplos podem comprovar que seu processo de criação, além de conturbado, é reflexo de uma escrita automática. Ao final de $O$ hóspede atrevido ou $O$ brilhante escondido, por exemplo, o autor revela que: "Esta comédia é apenas um borrão que deve passar pelas correções necessárias antes de ser impressa, tanto mais que foi escrita das 11 horas da noite de 30, às 3 quando muito da madrugada de 31." (QORPO-SANTO, 2001, p. 41). Também em Certa entidade em busca de outra, o autor diz: "Escusado é dizer que nada devem poupar os cômicos para tornar mais interessante e agradável o gracejo." (QORPOSANTO, 2001, p. 277) Já no verbete Espíritos aéreos, o autor declara:

Estou querendo... querem ver me-convenço!? corrijo 29:385 vezes este jornal antes de ir para o prelo, 984:689-depois de estar no prelo; e aind'assim depois de impresso noto erros e faltas como no fim se vêem... não há a menor duvida — os espíritos aéreos que produzião os efeitos extraordinários nas entranhas da descomunal mulher são - que alterão aquilo que escrevo, e que tantas mil vezes corrijo. (QORPO-SANTO, 2003, p. 109)

A última das dezessete peças do Teatro completo, Uma pitada de rapé, termina abruptamente em apenas uma cena incompleta, com a participação de duas personagens, Mário e A Filha. O fato de esta peça ter sido impressa pelo próprio autor junto às outras dezesseis completas revela mais uma vez a incompletude da obra. Como em $O$ castelo de Kafka, somos levados a cogitar se a quebra repentina no enredo teria ou não sido proposital. Para embasar esta assertiva levamos em consideração uma de suas outras peças, $O$ marinheiro escritor. Aqui, Qorpo-Santo, como é comum em seu teatro, muitas vezes meta-ficcional, parece fazer uma referência à Uma pitada de rapé, justificando talvez, através do título e associações, sua incompletude:

MIGUELÍTICO - Qual linha de conduta; nem traços de araruta!

ENCICLOPÉDIO - Pois, se a não quiseres seguir, hás de te arrepender!

MIGUELÍTICO - Eu não me posso arrepender do que faço sem querer.

ENCICLOPÉDIO - Ó diabo! Pois tu não queres?

MIGUELÍTICO - O quê? Não te entendo.

ENCICLOPÉDIO - Ó Miguelítico, ouves o que te estou dizendo?

MIGUELÍTICO - O que me dizes entra (apontando) pelo esquerdo e sai pelo direito. É o mesmo que uma pitada de rapé que se sorve e logo depois sai, assoando-se ou destilando-se. (QORPO-SANTO, 2001, p. 86)

O final do diálogo transcrito acima revela a qualidade efêmera do rapé, "que se sorve e logo depois sai, assoando-se ou destilando-se." Daí a nossa interpretação de que a incompletude da peça Uma pitada de rapé é proposital, tanto por seu título como pela associação feita pelo autor em $O$ marinheiro escritor. 
Outra condição de abertura na obra de Qorpo-Santo, além das observadas acima, diz respeito à constituição da obra completa. Em sua Ensiqlopédia não há critério seletivo: são poemas, comédias, reflexões sobre política, moral e ética, anúncios, bilhetes, máximas, confissões. Qorpo-Santo assim concebeu sua obra, sem distinções, por exemplo, entre poesia e recados para alguém, numa incrível nivelação literária para a época. $\mathrm{O}$ autor atribuiu noções similares a diferentes objetos textuais, levantando a questão do que vem a ser efetivamente a literatura e os gêneros literários. Se em sua época essa relativização ganhou ares de sandice, para a sensibilidade moderna é exatamente a falta de critério de assunto dos textos e a nivelação literária o que impressiona, principalmente por estar tão distante temporalmente desse tipo de discussão. O que vemos na leitura do que até então foi encontrado, pois ainda faltam três dos nove volumes da Ensiqlopédia, são retratos do ser humano, caótico, como caótica é nossa existência. O drama qorpossantense é impregnado de gritos de angústia e desespero, com cenas e diálogos imprevisíveis e um humor quase sempre cáustico.

O teatro de Qorpo-Santo é repleto desta caoticidade. Suas personagens adentram o palco como alucinações, são personagens intercambiáveis que mudam de nome, entram e saem do palco repentinamente, às vezes sem marcas cênicas para isto. Estas características afastam qualquer verossimilhança com uma realidade cotidiana, o que é também decorrência das mudanças de cenas bruscas e inesperadas. Muitas vezes, em grande parte de seu teatro, as cenas e os quadros findam sem realmente terem terminado. Cenas substituem outras que ainda não acabaram. Em $O$ marinheiro escritor, Dois irmãos e também $O$ marido extremoso ou $O$ pai cuidadoso, três de suas peças, essa mudança inesperada de cenas é bastante notável, vide os atos, quadros ou cenas serem diferentes retratos duma realidade quase sempre supra real. Em Dois irmãos, por exemplo, dos cinco quadros que integram a peça nenhum traz relação com o outro. São todos eles diferentes leituras de uma sociedade vista aos olhos argutos de um homem exilado e incompreendido por seus contemporâneos, crítico ferrenho das relações sociais.

Como no melodrama, estes aspectos do teatro qorpossantense revelam a possibilidade de introduzir acréscimos, o que prenuncia uma importante característica da literatura de vanguarda do século XX. Ao invés de um todo indissolúvel, partes conjugadas integram um todo multifacetado. Ou seja, ainda que de forma primária, o autor de As relações naturais produziu obras que se afastam de uma sequência linear e lógica. Para melhor explicarmos esta noção vanguardista recorremos à observação de Ernesto Sampaio, no prefácio à Teoria da vanguarda, de Peter Burger: 
Na obra de arte tradicional, as partes e o todo constituem uma unidade: o sentido das partes só pode ser revelado pelo todo, e este, por sua vez, só pode ser entendido através das partes. Na obra de vanguarda, pelo contrário, não existe nenhum todo que se sobreponha às partes, nem qualquer impressão geral que permita uma interpretação de sentidos. Como adiante dirá Peter Burger, "estas (as partes) já não estão subordinadas a uma intenção de obra". (SAMPAIO apud HUPPES, 2000, p. 31)

Ao trabalhar o objeto literário como uma espécie de pretexto para produzir certos efeitos, ao admitir que é um criador iluminado sob o pseudônimo de Qorpo-Santo, ao possibilitar o acréscimo de um desencontro, ou uma personagem flash, uma coincidência ou uma situação absurda, o dramaturgo gaúcho, mesmo sem ter consciência, emprega recursos que farão parte de uma tendência estética do século seguinte. Distante de retratar uma realidade perfeita ou moldá-la para que melhor se encaixe aos enredos, Qorpo-Santo enfatiza a invenção humana e seus problemas.

Embora inserido num contexto marcado principalmente pelo traço romântico, que a esta altura já perdera espaço para a comédia realista, o teatro de Qorpo Santo não congrega em momento algum as condições do Romantismo ou os limites e noções da pura realidade. $\mathrm{O}$ teatro que se fazia na época em que escreveu oscilava entre o drama romântico de Victor Hugo e Alexandre Dumas, famoso por sua A dama das camélias e mais tarde convertido à escola realista, e a comédia de costumes de Martins Pena, logo aprimorada por Joaquim Manuel de Macedo, França Júnior e Artur Azevedo. Apesar da tendência teatral de época, o drama de Qorpo-Santo está pautado sobretudo por uma ruptura com o mundo das aparências, com uma crítica mordaz às relações sociais. Ambientada nas possibilidades do inconsciente, na desconstrução do cotidiano, seu texto surge inovador se comparado aos padrões estéticos do período. Talvez, por esta razão, as peças de Qorpo-Santo tiveram que esperar cem anos para finalmente encontrar o refúgio e o entendimento devido, advindos principalmente das ideias dos movimentos de vanguarda expressas durante o século XX, da qual seu teatro, e também poesia, tantos anos antes, por muitas vezes se aproxima.

O sentimento de estar entre duas guerras, a Revolução Farroupilha (1835-1845) e A guerra do Paraguai (1864-1870), nos parece similar àquele vivenciado pelos autores europeus, como Kafka, Camus e Ionesco. Talvez essa sensação angustiante de presenciar os horrores de duas guerras praticamente ininterruptas é um dos pontos que aproxima QorpoSanto das vanguardas europeias do século XX, pelo menos no sentido do desespero e angústia que seus textos revelam. Esteticamente essa aproximação não é tão nítida, visto que o tempo de aproximadamente sessenta anos e a virada marcante do século XIX para o XX trouxe consigo diversas mudanças, algumas bruscas demais para se ter consciência. 
Flávio Aguiar, nesta perspectiva comparativista, observa como a dramaturgia de Qorpo-Santo se distingue do que se vinha criando em termos dramáticos até aquele momento.

Transposto para os textos dramáticos, o inconformismo latente na vida de Qorpo-Santo transformava-se na saudável libertinagem com que o autor tratara os cacoetes do teatro brasileiro do século XIX, sempre tão bem ajeitado e arrumado em seus enredos lógicos, em suas frases de efeito, em seu moralismo marcante, permitindo-se, de vez em quando, e sem grandes ofensas, um riso mais solto ou algumas lágrimas em excesso. Em lugar disso, QorpoSanto apresentava peças em que os enredos não tinham pé nem cabeça; a linguagem era violenta, direta, onde a retórica comparecia como recurso paródico. Personagens apareciam e desapareciam com rapidez meteórica; com frequência as falas não se articulavam logicamente, ganhando uma poeticidade bem ao gosto moderno". (AGUIAR, 1975, p.24)

Por razões como estas, Qorpo-Santo, além de se afastar das tendências teatrais de seu século, se manteve à parte do cenário literário brasileiro. Por isto, o reconhecimento da originalidade e estranheza da obra do autor só foi possível no século XX, sobretudo depois do surgimento das revoluções de arte que varreram a Europa.

Através deste conjunto de características que estruturam sua dramaturgia, desde a observação feita quando da impressão da obra, passando pelos trechos que diagnosticam uma incompletude do projeto enciclopédico, até a nivelação literária da Ensiqlopédia, Qorpo-Santo criou uma dramaturgia de grande diversidade, concedendo uma abertura ao leitor até então impensável. Por estas e outras razões que sua obra, especialmente o teatro, se aproxima de uma poética da obra aberta bem comum à literatura do século XX.

\section{Referências}

AGUIAR, Flávio Wolff de. Homens precários: inovação e convenção na dramaturgia de Qorpo-Santo. Porto Alegre: A Nação/Instituto Estadual do Livro, 1975.

BORGES, Jorge Luis. Ficções. Tradução de Carlos Nejar. 3. ed. - São Paulo: Globo, 2001.

COMPANGON, Antoine. O demônio da teoria: literatura e senso comum. Tradução de Cleonice Paes Barreto Mourão, Consuelo Fortes Santiago. Belo Horizonte: Ed. UFMG, 2001.

ECO, Humberto. Obra aberta: forma e indeterminação nas poéticas contemporâneas. São Paulo: Perspectiva, 1986.

FARIA, João Roberto. O teatro realista no Brasil: 1855-1865. São Paulo: Perspectiva: EDUSP, 1993.

FRAGA, Eudinyr. Um corpo que se queria santo. In: QORPO-SANTO, José Joaquim de Campos Leão. Teatro Completo. São Paulo: Iluminuras, 2001.

HUPPES, Ivete. Melodrama: o gênero e sua permanência. São Paulo: Ateliê Editorial, 2000.

KAFKA, Franz. O castelo. São Paulo: Companhia das Letras, 2004. 
SAAVEDRA, Miguel de Cervantes. Dom Quixote de la Mancha. São Paulo: Otto Pierre Editores, 1980.

QORPO-SANTO (José Joaquim de Campos Leão). Ensiqlopèdia, ou seis mezes de huma enfermidade: livro primeiro / José Joaquim de Campos Leão. - Dados Eletrônicos. - Porto Alegre : Tip. Qorpo Santo, 1877. Disponível em: <http://www.pucrs.br/biblioteca/qorposanto>

QORPO-SANTO (José Joaquim de Campos Leão). Miscelânea Quriosa. Denise Espírito Santo (org.). Rio de Janeiro: Casa da Palavra, 2003.

QORPO-SANTO (José Joaquim de Campos Leão). Teatro completo. Eudinyr Fraga (org.) São Paulo: Iluminuras, 2001. 